\title{
Antimicrobial prophylaxis for dental surgery
}

\section{Paul Sambrook \\ Chair \\ Dental Therapeutics \\ Committee \\ Australian Dental \\ Association \\ Sydney}

Aust Prescr 2017:40:230

https://doi.org/10.18773/

austprescr.2017.074
Antibiotic prophylaxis for most dental and oral surgical procedures is not needed, especially if the patient is fit and has no cardiac conditions. There is no evidence that it prevents postoperative infection.'

There are no studies that show a benefit from prophylactic antibiotics in patients undergoing routine dentoalveolar procedures. Procedures such as removal of teeth including third molars, biopsy of tissues within the mouth, scaling and cleaning, and even placement of dental implants, do not usually require prophylaxis. Antibiotic prophylaxis is considered if there is a risk of infective endocarditis. Practitioners must distinguish between prophylactic and therapeutic antibiotics. The management of established infection requires an adequate course of an antibiotic, which is effective against the most likely organism. If indicated, prophylaxis is often a single high dose. It is inappropriate to prescribe a so-called 'prophylaxis regimen' for more than five days, to give antibiotics 'just in case', or to use them when a procedure has become more complicated than expected.

Dental practitioners can refer to Therapeutic Guidelines: Oral and Dental, and Therapeutic Guidelines: Antibiotic. ${ }^{2}$ The patient's medical practitioner can also be consulted.

Conflict of interest: none declared

\section{REFERENCES}

1. Daly CG. Antibiotic prophylaxis for dental procedures. Aust Prescr 2017;40:184-8. https://doi.org/10.18773/ austprescr.2017.054

2. eTG complete [Internet]. Melbourne: Therapeutic Guidelines Limited; 2017. www.tg.org.au [cited 2017 Nov 1] 